\title{
Operation Night Watch: macro- and microscale X-ray imaging studies on the Rembrandt masterpiece The Night Watch in the Rijksmuseum
}

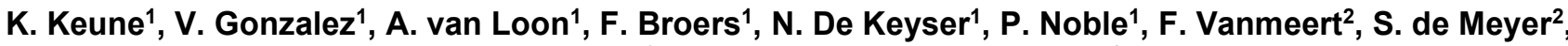 \\ K. Janssens ${ }^{2}$, Operation Night Watch-team ${ }^{1}$ \\ ${ }^{1}$ Rijksmuseum Amsterdam, The Netherlands \\ ${ }^{2}$ AXES Research Group, NANOLab Centre of Excellence, University of Antwerp, Belgium
}

\section{k.keune@rijksmuseum.nl}

Operation Night Watch is the largest research and conservation project that Rembrandt's masterpiece The Night Watch (1642, oil on canvas, h 378.4 x w $453 \mathrm{~cm}$ ) has ever undergone. In the summer of 2019, the Rijksmuseum embarked on this multi-year project with the goal of thoroughly studying the condition and painting technique to determine the best treatment plan for the large canvas painting. The Night Watch was researched in situ in the gallery inside an ultra-transparent glass chamber in full view of the public (Fig. 1). The multi-disciplinary team of Operation Night Watch includes scientists, conservators, and art historians, and collaborates with museums and universities in the Netherlands and abroad. Together they work alongside each other on the acquisition and interpretation of the research data.

The latest and most advanced research techniques are being used, ranging from digital imaging and scientific and technical research to computer science and artificial intelligence. The non-invasive macroscale imaging technologies that have been employed include macro X-ray fluorescence, macro X-ray powder diffraction, reflectance imaging spectroscopy, optical coherence tomography, high resolution photography and 3D scanning. The combined approach was essential to gain insight into the complex (art)historical and material information to answer the (technical) art history, conservation, and scientific questions. Parallel to this, microscale imaging analyses were carried out on embedded and loose microsamples making use of light microscopy, imagingATR-FTIR, scanning electron microscopy combined with X-ray elemental analyses, micro-Raman and synchrotron-based X-ray fluorescence and diffraction techniques in 2D and 3D mode.

During the lecture, examples will be given of the lead and arsenic sulphide-containing pigments that Rembrandt used in The Night Watch. The use, distribution, condition, and degradation products of these pigments will be discussed on both a macro and micro scale and the implications for the ensuing conservation treatment will be outlined.

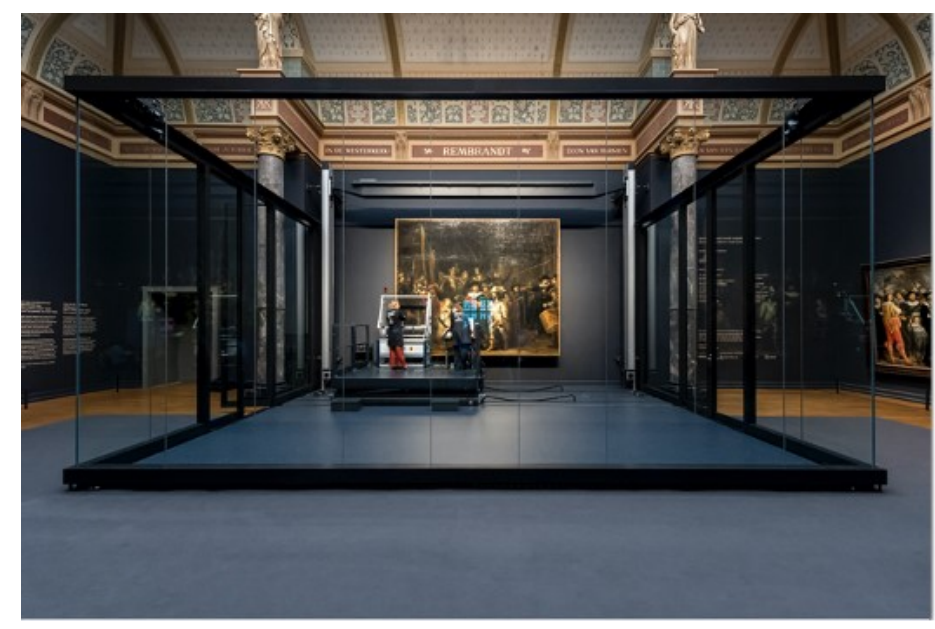

Figure 1. The Night Watch (1642) by Rembrandt van Rijn was investigated inside the glass chamber in the Gallery of Honour, Rijksmuseum, Amsterdam, The Netherlands

Keywords: painting, cultural heritage, imaging, X-ray powder diffraction, synchrotron 